\title{
The Emergence of Child Protection Capacities in Oman Lessons learned
}

"Shamsa S. Al Balushi, ${ }^{1,2}$ Gillian Morantz, ${ }^{2}$ Geoffrey Dougherty ${ }^{3}$

\begin{abstract}
Child maltreatment $(\mathrm{CM})$ is the abuse and neglect of children under the age of 18 years. Many types of CM lead to actual or potential harm to the child's health. It is a widespread phenomenon and is well reported in Western countries in contrast with the Gulf countries. Reports documenting CM in Oman are now available; therefore, this review aimed to provide an overview of the state and patterns of CM in Oman. It also addresses the current child protection services (CPS) in Oman and the sociocultural constraints. All English-language relevant medical literature about CM in Oman that were published before January 2020 were included. This review can serve as a basic reference in the field of CM in Oman and should help to identify lacunas in the current CPS as well as provide guidance in the establishment of a more effective one.
\end{abstract}

Keywords: Child Maltreatment; Child Protection Services; Child Advocacy; Oman.

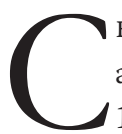

Hild MALTREATMENT (CM) IS DEFINED AS THE abuse and neglect of children under the age of 18 years. Many forms of CM result in actual or potential harm to the child, including physical and/ or emotional ill-treatment, sexual abuse, neglect, negligence and commercial or other exploitation. ${ }^{1} \mathrm{CM}$ is a widespread global phenomenon as summarised in a series of meta-analyses. ${ }^{2}$

Although CM is ubiquitous, its parameters, recognition and management vary by region and country. Compared to Western countries, there is a paucity of medical literature related to $\mathrm{CM}$ within the Gulf countries. ${ }^{3,4}$ According to Al-Mahroos, in the Arab Peninsula, medically reported cases most likely only represent the tip of the iceberg, while most of the less severe cases go unreported. ${ }^{4}$ Nevertheless, several reports documenting $\mathrm{CM}$ in Oman are now available in the medical literature.

Oman is a country in the Gulf Corporation Countries (GCC), which is a group of countries with cultural similarities. Oman has a fairly young population with half of the Omani citizens being below the age of $25 .{ }^{5}$ In the past four decades, Oman's socioeconomic status has been characterised by rapid development, resulting in improved standards of living and significant gains in health and education. This rapid development has also led to a shift from a traditional society towards a more modernised one with potential implications for the safety and wellbeing of Omani children. ${ }^{6}$

The United Nations Study on Violence Against Children prohibits all forms of violence against children in all settings as required by international treaties, including the Convention on the Rights of the Child, which was ratified by Oman in $19966^{7,8}$ Oman Child Law was implemented in 2014 and is often considered the biggest turning point towards an effective child protection services (CPS). It gave legal power to the CPS and the law consists of 79 articles that specify childrens' rights as well as protection measures and penalties for violating them. ${ }^{9}$

This review aimed to provide an overview of the state and patterns of CM in Oman until the year 2020. This review also addresses the current CPS in Oman and the sociocultural constrains when dealing with CM in Oman. This literature review should serve as a basic reference and as a background for further research in the field of child abuse and neglect in Oman.

\section{Methods}

This comprehensive literature review was conducted by reviewing all relevant medical literature about CM in Oman that were published in English before January 2020. Published reports were identified by searching the PubMed database and by using Google scholar.

The following terms were used during the search: child/physical/sexual/emotional/psychological/ Münchhausen's syndrome by proxy (MSBP) + abuse/ maltreatment/neglect + Oman. Discharge against medical advice (DAMA) was also included as a search term. DAMA is a situation where a caregiver removes a paediatric patient from the hospital against the medical team's recommendation. ${ }^{10}$ DAMA is considered a form of medical neglect, as it deprives 
a child of his/her medical rights. In addition, reports were obtained from references of articles and relevant conferences. The date of the last search was January 23, 2020.

\section{Results}

A total of 19 medical articles and reports were included in this review. ${ }^{3,11-27,38}$ One of these articles described child abuse potential inventory translation to Arabic, which is suitable to Oman, and two were published to advocate and raise awareness in the field of CM.,11,12 Most articles were case reports or case series providing descriptions of different forms of CM [Figure 1]. The following is a description of the remaining included studies. The first section includes the studies describing CM cases while the second section contains studies related to child protection capacities in Oman.

\section{PATTERNS OF CHILD MALTREATMENT REPORTED IN OMAN}

The first report on child abuse and neglect in Oman appeared in the year 2000. This report described five children with medical child abuse (formerly MSBP) from 1996-1999. Their ages were between 1-11 years. Uncontrolled epilepsy was the history given by the mothers of all five children. The delay in the diagnosis of MSBP was up to six years. ${ }^{13}$

In 2001, a case report of factitious hypoglycaemia, which described a child who first presented at the age of three years, was published. The child presented with multiple episodes of hypoglycaemia, sometimes with convulsion, up to the age of six years. He was lost to follow-up. A detailed psychosocial history of his mother (the alleged perpetrator) was provided and it included early childhood marriage twice with both marriages ending in divorce. ${ }^{14}$

In 2004, a survey was conducted on adolescent depression, which included questions on experiences of child abuse. The relationship with relatives, friends and teachers were assessed on a scale. It was found that $17 \%$ of the adolescents surveyed had depressive symptoms. Approximately $25 \%$ of them reported being subjected to physical abuse during adolescence by their caregiver. The study showed that physical abuse during adolescence significantly predicted depressive symptoms and that social support could have a buffering effect on depressive symptoms. ${ }^{15}$

In 2004, Al-Lamky published an exploratory review of the available literature in Oman (including Arabic papers) to examine child neglect as a social phenomenon. She highlighted some alarming trends and she concluded that they had harmful implications for the country's future development. Some of those trends were as follows: increasing divorce rates; short maternity leave; increasing reliance on untrained, expatriate and overburdened housemaids for raising children; and fathers' absence, often due to work and minimal involvement in their families. ${ }^{16}$

From 2006 until 2012, Al-Saadoon studied all cases suspected to be victims of medical child abuse registered at the Sultan Qaboos University Hospital, Muscat, Oman. A total of four children were identified

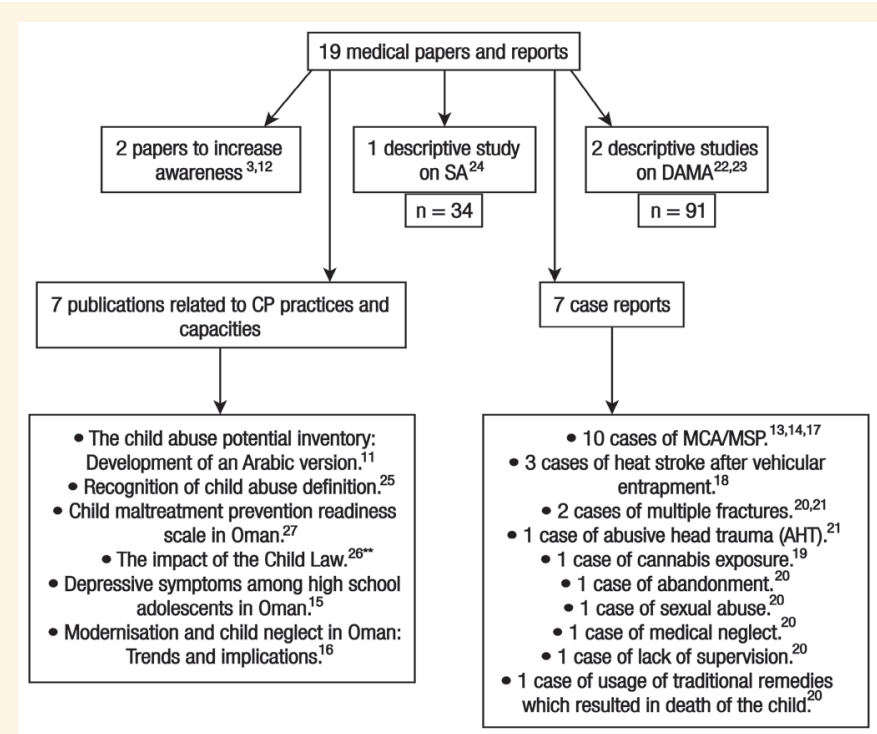

Figure 1: Flowchart summarising the results of the literature included in this review. ${ }^{3,11-27,38}$

$S A=$ sexual abuse; $D A M A=$ discharge against medical advice; $C P=$ child protection; $M C A=$ medical child abuse (formerly known as Munchausen Syndrome by Proxy [MSP]).

**Reported cases in less details: 25 cases of Neglect; DAMA (9 cases ); 4 cases of Physical abuse; 2 cases of sexual abuse; 1 case of emotional abuse 7 cases with more than one type of abuse. 
who were aged between 4-12 years. The cases presented with multiple unexplained symptoms (vomiting, headache, chest discomfort, palpitations and breathing difficulty). All of the alleged perpetrators had major psychosocial issues. Two out of the four cases reported using some type of physical abuse/punishment for the child, and in one case, there was a history of domestic violence among the couple. Due to the lack of child protection regulations at that time, it was not possible to enforce some of the management plans. The patients were evaluated by the hospital Child Protection (CP) team with the active involvement of the Ministry of Social Development. Children and mothers were also referred for psychiatric evaluation and management, but for three cases, the service was not utilised due to transportation issues or lack of interest. ${ }^{17}$

In 2010, a case report was published that reviewed three children who suffered from heat stroke after being trapped in vehicles. The mechanism of heat stroke in two of the reported children was car doors being left unlocked and the children entering into them without their parents' knowledge. All of the reported cases needed intensive care management and survived with residual brain damage. Two of the children were left with attention-deficit/hyperactivity disorder, while the third had active epilepsy. The article concluded by advocating against leaving children unattended in or around vehicles and concluded that this was a serious problem and a form of neglect. ${ }^{18}$

In 2011, a case report was published that described an Omani preschool child with cannabis exposure. She was brought by her parents to the Emergency Room four hours after the onset of symptoms (vomiting, abnormal eye movements, lethargy and inability to stand). The family had psychosocial and substance issues and loss of income. Her father removed her from the hospital against medical advice. Five days after discharge, tetracannabinoid substance was confirmed in the child's vomit. The child was reported to have hyperactivity and developmental delay in gross motor skills and language skills; prenatal/chronic cannabis exposure may have been a contributing factor to these issues. It was not mentioned in the report whether this case was reported to a higher authority. ${ }^{19}$

Between 2011 and 2013, Al-Saadoon et al. reported six cases of $\mathrm{CM}$. The first case described was a newborn who was abandoned by his mother after delivery. Since the criteria for placement in an orphanage states that only abandoned children of unknown parents are to be accommodated, the mother was forced to take the child into her care. The baby was brought back at the age of one month with bleeding from the nose and mouth and in cardiorespiratory arrest. Unfortunately, the baby died. The second reported case was a previously healthy 12-year-old girl admitted to the paediatrics intensive care unit with fulminant hepatic and multi-organ failure. The girl, unfortunately, died of acute mercury poisoning. Parents admitted that they had applied mercury as a traditional treatment for hair lice. The third case was a toddler who was playing unattended on a swing in her house. She was found hanging from the neck by the swing's rope and was given initial resuscitation at home; fortunately, the child survived. The fourth case was a 12-year-old girl who was diagnosed with inflammatory bowel disease and started on therapy. At follow-up, the child had uncontrolled symptoms and a non-reduction in inflammatory indices. The mother admitted to not giving the child her medications. The fifth case was a three-year-old boy who presented with aggression, remarkable changes in his behaviour and sexualised behaviours noted by his mother. The parents were separated, and the child went to the father's family home for weekly visits. The mother suspected recurrent sexual abuse of the child by three adolescent male relatives. The child was reported to have bruises around the anus. The boy's mother and the CP team made significant efforts, which put an end to the abuse. The child and mother received psychotherapy. The sixth case was an infant with recurrent episodes of limb fractures, including a fracture of the distal humerus during the neonatal period, a second fracture of the left femur and a third fracture of the humerus at the age of four years and six months. Investigations for bone diseases were negative at that stage. The parents denied any history of trauma and informed the $\mathrm{CP}$ team that they had sent an expatriate housemaid back to her country after the first event. Both parents believed that there was a jinn (spirit of evil) that was hurting their child. The parents were extensively counselled. The child was placed under close followup and no further injuries were noted. ${ }^{20}$

In 2013, Koul et al. reported a case of abusive head trauma (formally known as shaken baby syndrome; AHT). A five-month-old, previously healthy child, presented with a 10-day history of repeated tonic seizures, which were controlled with antiepileptic medication during admission. After discharge, the parents did not continue medication and he was admitted several times with breakthrough seizures. A brain magnetic resonance imaging (MRI) scan revealed a right-sided subdural haematoma. A metabolic workup (serum copper and urine organic acids) and a coagulation workup were carried out; the results were all normal. Microscopic examination of the hair (to identify kinked hair) revealed normal results. The ophthalmic examination also revealed normal results. The parents refused further workup, 
particularly a skeletal survey and left against medical advice. Two months later, the child presented with status epilepticus and swelling of the right knee. The skeletal survey revealed a healing fracture in the right radius and an acute fracture of the right distal femur. A follow-up electroencephalography revealed features of epileptic encephalopathy, and over time, he developed refractory seizures. Repeat brain MRI scan showed brain atrophy and resolution of the previous subdural haematoma. The CP team became involved and the parents agreed to follow the treatment recommendations at that time. Psychosocial evaluation of the family did not reveal any risk factors for inflicted injury. The authors concluded that there was no other cause found in this case except AHT. ${ }^{21}$

Two studies were conducted concerning DAMA. A significant number of the patients (57.9\%) were discharged against medical advice despite having potentially life-threatening health conditions such as septicaemia, acute abdominal pain and inflammatory diseases of the central nervous system. ${ }^{22}$ In more than half of the cases, the reasons for DAMA were not reported. When reported, the reasons cited for DAMA included the following: maternal perception of improvement in the child's condition (40.4\%) and social factors (e.g. arranging care for other children at home and the work commitments of the parents). In the prospective study, parents received a phone call two weeks later. The outcome of DAMA after two weeks indicated that $21.3 \%$ of the patients were still suffering from the same symptoms. In $4.3 \%$ of the cases, the interviewed mothers refused to reveal the condition of their child [Table 1]. ${ }^{22,23}$

In January 2020, a report was published on the characteristics and psychosocial effects of 34 children with a history of sexual abuse. ${ }^{24}$ This primarily consisted of case descriptions. Many of the published reports aimed to increase the level of awareness about CM in Oman and advocated for better child supervision and the establishment of an effective CPS [Table 2].

Table 1: Charactertistics of two studies concerning discharge against medical advice $\mathrm{e}^{22,23}$

\begin{tabular}{lcc} 
Characteristic & $\begin{array}{c}\text { Al-Sadoon et } \\
\text { al. }{ }^{22} \mathbf{2 0 1 3}\end{array}$ & $\begin{array}{c}\text { Al-Saadoon et } \\
\text { al. }^{\text {23 }}\end{array}$ \\
Study period & $2004-2006$ & 2013-2014 \\
$\begin{array}{l}\text { Type of study } \\
\text { Prevalence rate } \\
\text { of DAMA in \% }\end{array}$ & Retrospective & Prospective \\
Infants involved & Approximately two-thirds of the patients \\
& \multicolumn{2}{c}{ in both studies }
\end{tabular}

$D A M A=$ discharge against medical advice.

\section{CHILD MALTREATMENT CAPACITY DEVELOPMENT IN OMAN}

In 2013, 136 participants (social workers, nurses, psychologists and health educators) were involved in a five-hour workshop on child protection and were asked to complete a questionnaire with 19 statements that described scenarios of child abuse. The participants filled-in the questionnaire before starting and at the end of the workshop. The results indicated that physical abuse, emotional abuse and neglect were less likely to be identified compared to sexual abuse. The post questionnaire results showed improved recognition of the scenarios of CM. The article concluded that training of health professionals can improve their knowledge about what constitutes abusive practices, thereby leading to better recognition of CM. ${ }^{25}$

A further study was conducted to determine the impact of the Child Law between 2013 and 2015 (one year before and after the implementation of the Child Law). The study reviewing all the cases reported and registered during this period. There was a modest increase in the number of reported cases from 20 to 28 cases per year. The reported cases of DAMA, for example, increased from one to eight cases. According to the author, this was possibly explained by the increased recognition of the legal responsibility by the doctors after the implementation of the law. It was also observed that the Child Law helped in the standardisation of the reporting of all cases to the Child Protection Committee and in avoiding duplicated services being offered to the reported cases. The law also had a positive impact on the legal intervention process, follow-up and the services provided to the reported patients. ${ }^{26}$

In 2016, 49 key informants and decision-makers working in child protection were involved in a study on the readiness to implement the CM prevention programme using the World Health Organization's 10

Table 2: Characteristics of 34 children with a history of sexual abuse ${ }^{24}$

$\begin{array}{ll}\text { Characteristic } & \mathbf{n} \\ \text { Age }<12 \text { years } & 23 \\ \text { Female } & 22 \\ \text { Low family income } & 29 \\ \text { Abused by a first-degree relative } & 10 \\ \text { Abuse took place at the residence } & 28 \\ \text { Full sexual penetration } & 15 \\ \text { A pre-disclosure period of more than } 12 \text { months } & 23\end{array}$


dimensional readiness tool. The dimensions with the highest scores were noted to be legislation, mandates and policies followed by knowledge. The dimensions with the lowest scores were noted to be human and technical resources and attitudes. The overall score of the 10 dimensions was $50 .{ }^{17}$ which reflected a modest readiness of the country to provide a $\mathrm{CM}$ prevention programme. ${ }^{27,28}$

These papers aimed at exploring the current resources for CM prevention in Oman. The following section is a discussion of the current context and situation regarding $\mathrm{CM}$ in Oman as revealed by this literature review.

\section{Discussion}

In this section, the reported CM cases in the Omani literature are discussed, contrasted and compared to the international data under four headings. The overall perception of CM data is presented first, followed by a discussion of the characteristics of the reported cases. Risk factors associated with $\mathrm{CM}$ cases are presented. The final section concerns the reported child protection response to CM cases.

\section{CHILD MALTREATMENT DATA FROM OMAN}

This review of the literature on CM in Oman revealed that Omani children are subjected to all known forms of CM. No national cross-sectional prevalence studies on $\mathrm{CM}$ were identified during this literature review, and due to the relative paucity of data from Oman, it was difficult to estimate whether the magnitude of $\mathrm{CM}$ in Oman is similar to what is seen in other parts of the world. It was noted that there has been an increase in publications from Oman concerning CM in recent years, which might be due to the increase in the number of professionals with an interest in this field and an increase in awareness among professionals, particularly since the implementation of the Child Law in 2014. The first report on CM in Oman appeared in the year 2000, which appears somewhat late compared to the first cases of $\mathrm{CM}$ worldwide which was reported in $1962 . .^{29}$

\section{CHARACTERISTICS OF CHILD MALTREATMENT IN OMAN}

Most of the reports concerning CM were found to be hospital-based and usually represented very severe forms of CM, such as AHT and neglect leading to death, or other forms of CM such as DAMA, medical child abuse and accidental injuries as a possible result of neglect. There were very few available reports in the Omani medical literature on the more common forms of CM, such as inflicted bruises and fractures. This might reflect that physical abuse may be tolerated and often accepted as a form of physical discipline. Another explanation for a lack of such data is that primary care physicians, who see such injuries first, fail to identify these cases. Professionals, in general, may be unaware of the signs for CM as well as their legal responsibilities. This lack of recognition of CM seemed to have been particularly pervasive before the implementation of the Child Law, which was evidenced by the increase in reported cases as demonstrated in the study on the impact of the Child Law. ${ }^{26}$

Similarly, any mention of psychological maltreatment including exposure to domestic violence, was conspicuously absent from the Omani literature. Medical child abuse was the first identified type of CM in the Omani medical literature and it continued to be the only reported type until 2010.

Only one case of AHT has been published in the Omani literature thus far. It is known that AHT is less often seen and reported in the GCC countries. ${ }^{21}$ However, AHT can have a subtle clinical presentation and potential cases may have been going unrecognised and/or unreported. In the one case reported in the Omani literature, there was a delay in obtaining head imaging as well as ancillary testing, which may have resulted in a delayed diagnosis. Aiming to increase awareness about this type of CM, Al-Saadoon et al. published an advocacy paper in $2011 .^{3}$

The authors opine that the prevalence of child sexual abuse is possibly lower in Oman compared to worldwide averages because of its culture, but in order to reach such a conclusion extensive population-wide research would be required. Only 37 cases of sexual abuse have been reported so far. This is not likely to be the actual number in the community and many sexual abuse victims may not be brought to medical or legal attention by caregivers, possibly due to a culture of 'silence' surrounding this issue. Al Shekaili et al. concluded that that the patterns of sexual abuse seemed to be similar to the trends worldwide given that the majority of the Omani sexual abuse victims were female and aged below 12 years. ${ }^{30,31}$ However, it was a study with a small sample size and it included only cases referred for rehabilitation, which could have had biases due to the culture around female sexual abuse compared to male sexual abuse. ${ }^{24}$

DAMA is a significant issue in Omani hospitals and it deprives a child of his/her right to necessary medical care. In some cases, children's lives could have been placed at risk. The studied prevalence rate of DAMA in Oman was $0.32-1 \%$, which was comparable to a worldwide rate estimated to be approximately 
$1 \%{ }^{32-34}$ Social problems are the major reasons cited for DAMA in Oman.

Only one case report proved that a child was exposed to cannabis, and in this report, the child was discharged against medical advice. Furthermore, there was no mention in the report about whether the CP team was engaged.

Neglect is reported indirectly as was seen in three cases of vehicular entrapment resulting in heat stroke and significant neurological sequelae and one case of lack of supervision resulting in a child being strangulated by a swing.

Omani adolescents with a history of physical abuse were found to be more likely to have depression. This finding was comparable to international studies that revealed that abused adolescents showed significantly higher prevalence rates of depression, conduct disorder, suicide and substance abuse..$^{35,36}$

\section{RISK FACTORS FOR CHILD MALTREATMENT IN OMAN}

Similar to the international medical literature, difficult socioeconomic conditions appeared to be major risk factors for child abuse in Oman. These factors included divorced parents, early marriages and lack of social support. Some mothers of abused children were themselves abused during their childhood and had psychological consequences that were likely left untreated.

Other socioeconomic issues that were mentioned included poverty, lack of parental medical literacy, beliefs in traditional medicine and loss of trust in health services. This suggests that primary and secondary CM prevention strategies might be effective in reducing $\mathrm{CM}$ as in other jurisdictions. ${ }^{37}$ In addition, it was found that a lack of child protection intervention in some cases allowed abuse to continue. ${ }^{19-21}$

Certain social attitudes and traditional cultural practices were found to represent another challenge for the efforts to address CM prevention in Oman. Belief in evil spirits such as a jinn was a reason provided by some caregivers to explain abnormal behaviours of the abused child and for DAMA. The practice of remaining silent and fear of social taboo linked to sexual abuse resulted in fewer children being rehabilitated after abuse; these were found to be risk factors for continued child abuse.

\section{RESPONSE TO CHILD MALTREATMENT \\ AND THE CURRENT CHILD PROTECTION SERVICES}

This review suggested that until recently, there had been a lack of child protection response to CM cases in Oman, especially prior to the implementation of the Child Law in 2014. Abused children were most often returned to their homes despite the certainty of abusive environments; many continued to suffer without psychological rehabilitation and some died without protection. Monitoring of victims through hospital-based appointments or home visitation by child welfare services was rare and this led to a loss of the opportunity to monitor a maltreated child. In most cases, alleged perpetrators did not receive any educational interventions or face criminal punishment, nor were safety measures put into place. Regarding mental health services, there are only two institutes in Oman that provide child and adolescent mental health services. They offer services to the whole country and are both located in the capital. ${ }^{38}$

After the implementation of the Child Law, there was an increase in the number of reported cases and an improvement in the follow-up, legal intervention and services provided to the reported patients. ${ }^{26}$ In 2016, Child Protection Delegates were appointed and they are considered judicial police. Currently, there is a child helpline as well as child protection committees in all Omani regions. ${ }^{26}$

\section{LESSONS LEARNED AND THE WAY FORWARD}

The magnitude and the actual prevalence of CM in Oman were found to be difficult to estimate from what has been published to date. This review highlighted the need to further understand the prevalence and patterns of CM in Oman through population-based studies in order to inform Omani child protection policy and programming. Further research into the more common forms of CM (i.e. inflicted bruises and fractures) should be pursued. A review of the literature revealed that until recently, Oman's CPS was significantly lacking in terms of effectiveness; in light of this, a detailed specific review for the current CPS is recommended. This review also highlighted a lack of effective community-based services, such as family counselling programmes, to teach parenting skills. Several such secondary prevention interventions have proven successful in other settings. It is important to continue to develop and implement culturally adapted community awareness CM prevention programmes. This review suggested that the role of CM awareness campaigns in the general community and among professionals caring for children, such as teachers and social workers, is important. In addition, social support services may help prevent DAMA occurrences and buffer depressive symptoms among abused children. There is a need to ensure access to rehabilitation and treatment for abused children as well as the provision of a larger number of mental health services that are 
more easily accessible. Penal sanctions should be made more explicit so that they can act as a deterrent to potential perpetrators. There should be an opportunity for permanent placement in certain severe cases of abuse, such as kinship placement with relatives or even a foster care system.

\section{Conclusion}

Oman has made significant progress in the field of CM. Social, medical and legal capacity to support the continuing promotion of CM systems can and should be further developed.

\section{AUTHORS' CONTRIBUTION}

SSB and GD conceptualised and designed the review. SSB performed the literature review and collected the data. SSB and GM analysed and discussed the data. SSB drafted the manuscript, while GM and GD revised the manuscript. All authors approved the final version of the manuscript.

\section{References}

1. World Health Organization. Child maltreatment, 2016. From: https://www.who.int/news-room/fact-sheets/detail/childmaltreatment Accessed: Jan 2020.

2. Stoltenborgh M, Bakermns-Kranenburg MI, Alink LRA, van Ijzendoorn $\mathrm{MH}$. The prevalence of child maltreatment across the globe: Review of a series of meta-analyses. Child Abuse Rev 2015; 24:37-50. https://doi.org/10.1002/car.2353.

3. Al-Saadoon M, Elnour I, Ganesh A. Shaken baby syndrome as a form of abusive head trauma. Sultan Qaboos Univ Med J 2011; 11:322-7.

4. Al-Mahroos F. Child abuse and neglect in the Arab Peninsula. Saudi Med J 2007; 28:241-8.

5. Ministry of Health, Oman. Annual Health Report 2018. Table 1-1: Population Characteristics (Omani Population) Page 4. From: https://www.moh.gov.om/en/web/statistics/-/20-59 Accessed: Dec 2020.

6. Al-Adawi S. Tomorrow's people matters: Evidence for action in Oman. Oman Med J 2014; 29:83-5. https://doi.org/10.5001/ omj.2014.21.

7. United Nations. Legal ban on violence against children. From: https://violenceagainstchildren.un.org/content/legal-banviolence-against-children Accessed: Dec 2020.

8. UNICEF Oman. Charting progress towards child protection in Sultanate of Oman - Findings of a national consultative workshop. Muscat, Oman: UNICEF. P.6.

9. Ministry of Social Development, Oman. Oman Child Law. From: https://www.mosd.gov.om/images/rules/Childs\%20Law \%20en.pdf Accessed: Dec 2020.

10. Alfandre DJ. "I'm going home": Discharges against medical advice. Mayo Clin Proc 2009; 84:255-60. https://doi.org/10.1016/S00 25-6196(11)61143-9.

11. Al Abduwani J, Sidebotham P, Al Saadoon M, Al Lawati M, Barlow J. The child abuse potential inventory: Development of an Arabic version. Child Abuse Negl 2017; 72:283-90. https:// doi.org/10.1016/j.chiabu.2017.08.012.
12. Al-Lamki L. Child rights: What can we do in Oman? Sultan Qaboos Univ Med J 2012; 12:1-4. https://doi.org/10.12816/0003081.

13. Koul RL, Chacko A, Al-Lamki Z, Al-Amri AM, Al-Khusaiby S. Munchausen syndrome by proxy. Saudi Med J 2000; 21:482-6.

14. Bappal B, George M, Nair R, Khusaiby SA, De Silva V. Factitious hypoglycemia: A tale from the Arab world. Pediatrics 2001; 107:180-181.

15. Afifi M, Al Riyami A, Morsi M, Al Kharusil H. Depressive symptoms among high school adolescents in Oman. East Mediterr Health J 2006; 12:S126-37.

16. Al-Lamky A. Modernization and child neglect in Oman: Trends and implications. Int J World Peace 2004; 21:43-53.

17. Al-Saadoon M. Munchausen syndrome by proxy (MSBP): Difficulties of applying diagnostic criteria. Poster presented at: 13th ISPCAN European Regional Conference on Child Abuse and Neglect; 2013 Sep; Dublin, Ireland.

18. Koul R, Al-Futaisi A, Al-Sadoon M, El-Nour I, Chacko A, Hira $M$, et al. Vehicular entrapment and heat stroke in three children: Is it a form of child neglect? Oman Med J 2010; 25:222-4. https://doi.org/10.5001/omj.2010.61.

19. Al-Shidhani TA, Arora V. Cannabis exposure in an Omani child: First case report from Oman. Sultan Qaboos Univ Med J 2011; 1:511-14.

20. Al-Saadoon M, Al-Sharbati M, Nour IE, Al-Said B. Child maltreatment types and effects: Series of six cases from a university hospital in Oman. Sultan Qaboos Univ Med J 2012; 12:97-102.

21. Koul R, Poothrikovil R, Al-Azri F, Al-Sadoon M. Evolution of epileptic encephalopathy in an infant with non-accidental head injury. Neurosciences (Riyadh) 2013; 18:264-8.

22. Al-Sadoon M, Al-Shamousi K. Discharge against medical advice among children in Oman: A university hospital experience. Sultan Qaboos Univ Med J 2013; 13:534-8.

23. Al-Saadoon $\mathrm{M}, \mathrm{Al}$ Mahrouqi $\mathrm{H}, \mathrm{Al}$ Jaafari $\mathrm{N}, \mathrm{Al}$ Maawali $\mathrm{H}$. Reasons of discharge against medical advice among children in Oman: SQUH experience. Poster presented at:14th ISPCAN European Regional Conference on Child Abuse and Neglect; 2015 Sep; Bucharest, Romania.

24. Alshekaili M, Alkalbani Y, Hassan W, Alsulimani F, Alkasbi S, Chan MF, et al. Characteristic and psychosocial consequences of sexually abused children referred to a tertiary care facility in Oman: Sentinel study. Heliyon 2020; 6:e03150. https://doi. org/10.1016/j.heliyon.2019.e03150.

25. Al Saadoon M, Al Hadifi F, Al-Said B. Recognition of child abuse: Are we using same definition. Poster presented at: ISPCAN Asia Pacific Regional Conference on Child Abuse and Neglect; 2015 Oct; Malaysia.

26. Al Saadoon M. Impact of child law on hospital protection services: Sultan Qaboos University Hospital (SQUH) experience. Poster presented at: ISPCAN Asia Pacific Regional Conference on Child Abuse and Neglect; 2015 Oct; Malaysia.

27. Al Saadoon $\mathrm{M}, \mathrm{Al}$ Numani A, Saleheen $\mathrm{H}$, Almuneef $\mathrm{M}, \mathrm{Al}$ Eissa M. Child maltreatment prevention readiness assessment in Oman. Poster presented at: the 2019 ISPCAN Congress and the 6th Arab International Child Abuse and Neglect Conference; 2019 Sep 15-17; Muscat, Sultanate of Oman.

28. Al Eissa $M$, Saleheen $H$, Almuneef $M$, Al Saadoon $M$, Alkhawari M, Almidfa A, et al. Child maltreatment prevention readiness in Gulf Cooperation Council (GCC) countries. Int J Pediatr Adolesc Med 2019; 6:92-100. https://doi.org/10.1016/j. ijpam.2019.07.009.

29. Kempe CH, Silverman FN, Steele BF, Droegemueller W, Silver HK. The battered-child syndrome. JAMA 1962; 181:17-24. https:// doi.org/10.1001/jama.1962.03050270019004. 
30. Barth J, Bermetz L, Heim E, Trelle S, Tonia T. The current prevalence of child sexual abuse worldwide: A systematic review and meta-analysis. Int J Public Health 2013; 58:469-83. https://doi.org/10.1007/s00038-012-0426-1.

31. Kim H, Drake B. Cumulative prevalence of onset and recurrence of child maltreatment reports. J Am Acad Child Adolesc Psychiatry 2019; 58:1175-83. https://doi.org/10.1016/j.jaac.2019.02.015.

32. Okoromah CN, Egri-Qkwaji MT. Profile of and control measures for paediatric discharges against medical advice. Niger Postgrad Med J 2004; 11:21-5.

33. Aliyu ZY. Discharge against medical advice: Sociodemographic, clinical and financial perspectives. Int J Clin Pract 2002; 56:325-7.

34. Gloyd S, Koné A, Victor AE. Pediatric discharge against medical advice in Bouaké Cote d'Ivoire, 1980-1992. Health Policy Plan 1995; 10:89-93. https://doi.org/10.1093/heapol/10.1.89.
35. Pelcovitz D, Kaplan S, Goldenberg B, Mandel F, Lehane J, Guarrera J. Post-traumatic stress disorder in physically abused adolescents. J Am Acad Child Adolesc Psychiatry 1994; 33:305-12. https://doi.org/10.1097/00004583-199403000-00002.

36. Kaplan SJ, Pelcovitz D, Salzinger S, Mandel F, Weiner M. Adolescent physical abuse and suicide attempts. J Am Acad Child Adolesc Psychiatry 1997; 36:799-808. https://doi. org/10.1097/00004583-199706000-00017.

37. Chaffin M, Friedrich B. Evidence-based treatments in child abuse and neglect. Children and Youth Services Review 2004; 26:1097-113. https://doi.org/10.1016/j.childyouth.2004.08.008.

38. Mirza H. Child and adolescent mental health services in Oman. London J Prim Care (Abingdon) 2018; 10:121-2. https://doi.or $\mathrm{g} / 10.1080 / 17571472.2018 .1482661$. 